\title{
Effects of Various parameters on Radiative Transfer Theory Based Microwave Emission Model
}

\author{
Mazen E. Assiri \\ Department of Meteorology, Faculty of Meteorology, Environment and Agriculture of Arid Land, \\ King Abdulaziz University, Jeddah, King Saudi Arabia \\ Massiri1@kau.edu.sa
}

\begin{abstract}
This paper outlines research that is currently being carried out to model the interaction of electromagnetic radiation with earth and atmosphere. Among many others, passive microwave (PM) imagery represents a useful source of data for mapping Earth features. Since, signal of a microwave radiometer is composed of surface and atmospheric contributions, for proper interpretation of the data these effects should be quantified. This research presents analysis of radiative transfer model contributors, which include; the ground based parameters, forest area, water area, and meteorological parameters. The principal objective of this study is to analyze the degree to which brightness temperature can be affected by various earth and atmospheric features. A sensitivity analysis is performed to test the contributing effects of various parameters in radiative transfer theory based microwave emission model. The results of the study show that soil temperature and forest stem volume are the main contributing parameters in estimating brightness temperature values. The results further show that both the earthly located features and atmospheric parameters are important factors that must be taken into account in the development and application of radiative transfer theory based models.
\end{abstract}

Keywords: Passive Microwave, radiation, brightness temperature, electromagnetic radiation, model, meteorological parameters.

\section{Introduction}

Every natural substance radiates electromagnetic energy at a finite absolute temperature. When an electron transits from one atomic energy level to another energy level, it emits energy in the form of radiation (called a photon). The frequency of this photon is calculated using equation (1).

$$
f=\frac{\varepsilon_{1}-\varepsilon_{2}}{h}
$$

Where $\varepsilon_{1}$ and $\varepsilon_{2}$ are the energy levels of electron in an atomh is the Plank's constant $\left(6.634 * 10^{-34} \mathrm{~J}\right.$ sec )

Remote Sensing is the collection of information about an object without coming into physical contact. Remote sensing of earth observations started to be used in the early 1970s particularly but not limited in the fields of meteorology, oceanography, glaciology, geology, topography and cartography, agriculture, hydrology, urban planning, and military intelligence (Rees, 1993). Currently 
there are many satellites and airborne sensor systems, sensitized to naturally emitted and/or reflected radiation from the earthly located objects, that are used widely by Earth observation scientists. A relation therefore is needed in order to explain the process of emission and reflection (or interaction) of electromagnetic radiation sensed by the sensor (Lakshmi, et al., 1997; Jin and Zhang 1999; Kokhanovsky, 2001; Ding, et al., 2010; Lemmetyinen, et al., 2013). The electromagnetic radiation, hence, is one of the key elements in these remote sensing systems.

When an electromagnetic wave interacts with a suspended material particle, fraction of it is absorbed and another fraction is scattered (depends on the size of target particles and the wavelength of the incident wave) by the particle. During the scattering process, a portion of the incident wave is scattered backward and the rest is transmitted forward towards the lower medium. If the lower medium is homogeneous, the scattering will take place only at the surface boundary whilst if the lower medium is heterogeneous, then the wave transmitted into the lower medium is also scattered backward and may cross the boundary of the upper medium. The particle may undergo either Mie scattering (if size of the scattering particles is comparable to the wavelength of the light) or Rayleigh scattering (if size of the scattering particles is much smaller than the wavelength of the light). In case of Mie scattering equation (2) is used to estimate the scattering parameter while equation (3) is used when the medium is heterogeneous (Ulaby, et al. 1981).

$\chi=k_{b} r=\frac{2 \pi r}{\lambda_{b}}=\frac{2 \pi r}{\lambda_{0}} \sqrt{\epsilon_{r b}^{\prime}}$

and

$n=\frac{n_{p}}{n_{b}}=\left(\frac{\epsilon_{c p}}{\epsilon_{c b}}\right)^{1 / 2} \underline{\Delta} \epsilon_{c}^{1 / 2}$ $\chi$ is the Mie size parameter.

$k_{b}$ is the wave number in the background medium.

$\epsilon_{r b}^{\prime}$ is the real part of the relative dielectric constant of the background medium

$\lambda_{b}$ is the wavelength in the background medium.

$\lambda_{0}$ is the free space wavelength.

$n$ is the complex index of refraction.

$n_{p}$ is the complex index of refraction of the particle material of the background medium.

$n_{b}$ is the complex index of refraction of the sphere material of the background medium.

$\epsilon_{c}$ is the complex dielectric constant.

$\epsilon_{c p}$ is the complex dielectric constants for the particle material of the background medium.

$\epsilon_{c b}$ is the complex dielectric constants for the sphere material of the background medium.

For Rayleigh scattering equation (4) is used to measure the scattering parameter.

$Q_{s}=\frac{2 \lambda^{2}}{3 \pi} \chi^{6}|K|^{2}$

And

$Q_{a}=\frac{\lambda^{2}}{\pi} \chi^{3} \operatorname{Im}|-K|$

where

$\mathrm{Q}_{\mathrm{a}}$ and $\mathrm{Q}_{\mathrm{s}}$ are the absorption and scattering cross-section

$\mathrm{K}$ is the complex quantity given as:

$$
K=\frac{n^{2}-1}{n^{2}+2}=\frac{\epsilon_{c}-1}{\epsilon_{c}+2}
$$

However, for microwave sensors, the brightness temperature is estimated using equation (7) (Kirchoff's Law).

$\mathrm{a}=\mathrm{e}$

where

a is the absorptivity

$\mathrm{e}$ is the emissivity

where 
Similarly, the brightness temperature that is equivalent to radiometer temperature is calculated using equation (8).

$T_{\beta B}(\theta, \phi)=I_{\beta}(\theta, \phi) \frac{\lambda^{2}}{K}$

where

$I_{\beta}(\theta, \phi)$ is the specific intensity emitted by object.

$\beta$ is the polarization.

$(\theta, \phi)$ is the angular direction.

$\lambda$ is the wavelength.

$\mathrm{K}$ is the Boltzmann constant.

For uniform physical temperature (the degree of heat in an object that is related to the average kinetic energy of the atoms or molecules of the object) the term emissivity $\mathrm{e}_{\beta}$ $(\theta, \phi)$ is calculated from equation (9).

$e_{\beta}(\theta, \phi)=\frac{T_{\beta B}(\theta, \phi)}{T}$

where

$\mathrm{T}$ is the physical temperature of the object.

However, the values of all brightness temperatures depend on frequency and polarization with vertical polarization has slightly higher value of brightness temperature than horizontal polarization due to transmission properties of materials (Barnes, et al., 1981).

The main objective of current research is to analyze the contributing effects of various parameters (ground based parameters, forest area, water area, and meteorological parameters) involved in the radiative transfer theory based microwave emission model. For this, a standard radiative transfer model that incorporates atmospheric and surface contribution is used in this study. The process parameters evaluated by a procedure known as optimisation are used in the analysis. Sensitivity test of soil, forest, water and atmospheric parameters is conducted to determine the impact of parameters on the estimated brightness temperatures from the model.

\section{Microwave Remote Sensing}

Electromagnetic radiation with frequencies between $300 \mathrm{MHz}$ to $300 \mathrm{GHz}$ (wavelength between $0.1 \mathrm{~cm}$ to $100 \mathrm{~cm}$ ) are termed as microwaves. Microwaves are shorter than radio wave but longer than infrared radiation. A remote sensing system can measure electromagnetic radiation in the visible to microwave range (Loth and Graf 1998; Kumar, et al., 1999). Visible $(0.4-0.7 \mu \mathrm{m})$ and near infrared (0.7-1.0 $\mu \mathrm{m})$ channel instruments measure the amount of sunlight reflected from the surface and thereby are hampered with cloudy conditions as the information obtained is due to molecular resonances in the surface layer of the material under investigation (Lundien, 1971; Hollinger, et al., 1990; Colton and Poe, 1999). On the other hand, microwave remote sensing provides the potential for obtaining near-allweather (cloud penetrating) observations as the information obtained from microwave imagery is the result of geometric and bulkdielectric properties of the surface or volume studied (Ulaby, et al., 1981; Ulaby et al., 1986a, b; Schiavon, et al., 1998; Wiesmann and Matzler, 1999; Mätzler, 2005). Microwave radiometers measure signatures that can provide information for the identification of various surface features (Leschanskiy, et al., 1971; Hoekstra and Delaney, 1974; Davis, et al., 1976; Newton, 1977; Fung and Chen, 1981; Yang, et al., 1997; Standley and Barrett, 1999; Mätzler and Melsheimer, 2006; Picard, et al., 2013). The microwave portion ranges from $1 \mathrm{GHz}$ to $300 \mathrm{GHz}$ in frequency $(1 \mathrm{~mm}$ to $30 \mathrm{~cm}$ in wavelength) of electromagnetic spectrum. In the microwave region we come across two different types of remote sensing, that is, passive and active. Passive microwave remote sensing (between $0.1 \mathrm{~cm}$ to $1 \mathrm{~m}$ of wavelength and $30 \mathrm{MHz}$ to $300 \mathrm{GHz}$ of frequency) measures the natural upwelling radiation emitted by the surface of the earth. On the other hand, in active remote sensing 
system, a radar sends microwave pulses towards the ground and measures the reflected signal or backscattering coefficient. Nevertheless, passive microwave remote sensing has attracted investigators for many years since it can provide useful information for various hydrological, climatological and meteorological applications under most sky conditions (Chang, 1997; Kunzi, et al., 1982; (Mätzler and Rosenkranz, 2007).

In recent decades many research groups have developed global and regional brightness temperature retrieval models using passive microwave radiometric data. Developing a simple model to retrieve the earth parameters from brightness temperature values is not straight forward (Matzler, 1990) as the microwave models available are highly dependent on local environmental and climatological conditions (Anderson and Tice 1971; Butt 2002a; 2002b; 2002c; Mätzler and Melsheimer, 2006; Mironov, et al., 2010; Rautiainen, et al., 2012). Thus, the accuracy of microwave model is not yet good enough for operational use (Hallikainen, 1989). The next section focusses on the radiative transfer theory based microwave emission model.

\section{Methodology}

Equation of radiative transfer has wide variety of applications in the field of remote sensing. The electromagnetic radiation undergo the processes of absorption, emission and scattering when interacting with a medium. Radiative transfer theory explains the physical phenomenon of energy transfer through that medium. The microwave emission model based on radiative transfer theory presented by Pulliainen, et al. (1999) is given as:

$$
\begin{aligned}
B= & T(\theta) B_{\text {gnd }}(\theta)+B_{\text {atm. }}(\theta)+ \\
& T(\theta)\left(1-E_{\text {gnd }}(\theta)\right) \cdot \\
& {\left[B_{\text {atm }}(\theta)+T(\theta) \cdot 2.7\right] }
\end{aligned}
$$

where
$T$ is the atmospheric transmissivity

$B_{\text {gnd }}$ is the brightness temperature of ground scene

$B_{\text {atm, } \uparrow(\downarrow)}$ is the up(down)welling atmospheric brightness temperature

$E_{\text {gnd }}$ is the emissivity of the ground scene

$\theta$ is the angle of radiation propagation

In equation (10) the brightness temperature of ground scene can be estimated using equation (11), given by Pulliainen et al. (1999) as:

$$
B_{\text {gnd }}(\theta)=F_{\text {for }} B_{\text {for }}(\theta)+\left(1-F_{\text {for }}\right) B_{\text {soil }}
$$

where

$F_{f o r}$ is the percentage of land surface cover by forest

$B_{f o r}$ is the brightness temperature contribution of the forested land

$B_{\text {soil }}$ is the brightness temperature contribution of the soil land

In equation (11) the brightness temperature contribution of soil land is presented by Wegmuller and Matzler (1999) in the 1-100 $\mathrm{GHz}$ (both for $\mathrm{H}$ and $\mathrm{V}$ polarisation) range and for incidence angle between $20^{\circ}$ and $70^{\circ}$. They used three sources of microwave data for the derivation of the model: first two were the measurements of a ground-based passive microwave radiometer (PAMIR) and radiometer and scatterometer (RASAM) whilst the third is the measurements made with a laser profiler, taken from Wegmuller (1986) and Stotzer, et al. (1986). PAMIR is a multifrequency microwave (4.9 and $94 \mathrm{GHz}$ at linear polarisation) radiometer which measure reflectivity over 14 situations of bare soils, together with additional information on soil moisture and surface roughness from 1989 to 1992, summarised by Matzler (1992). On the other hand, RASAM measures (frequencies between 2 and $12 \mathrm{GHz}$ ) brightness temperature both at horizontal (H) and vertical (V) polarisation and the backscattering coefficient at $\mathrm{HH}-, \mathrm{VV}-, \mathrm{HV}-$ and $\mathrm{VH}-$ polarisation at incidence angles from 0 to $70^{\circ}$ over 
agricultural fields (for example, bare soil, maize, wheat, potato, oat and barley) between 1984 and 1992 under various environmental conditions. These were summarised in a signature database (Wegmuller and Matzler 1993) and were the second source of microwave data. Wegmuller and Matzler (1999) used rough bare soil reflectivity model as given in equation (12).

$$
\begin{aligned}
R_{h, \text { mod }}(m v, k s, \theta)= & R_{h, \text { Fresnel }} \cdot \\
& \exp \left\{-(k s)^{\sqrt{0.10 \cos \theta}}\right\}
\end{aligned}
$$

The model for vertical polarisation is divided into two parts (equation, 13 and 14). The first is for $\theta \leq 60^{\circ}$

$$
\begin{gathered}
R_{v, \text { mod }}(m v, k s, \theta)=R_{h, \text { mod }}(m v, k s, \theta) . \\
(\cos \theta)^{0.655}
\end{gathered}
$$

and for $60^{\circ} \leq \theta \leq 70^{\circ}$

$$
\begin{aligned}
R_{v, \text { mod }}(m v, k s, \theta)= & R_{h, \bmod }(m v, k s, \theta) . \\
& \left(0.635-0.0014 \cdot\left(\theta-60^{\circ}\right)\right)
\end{aligned}
$$

Where

$R_{h, \text { Fresnel }}(\theta)$ is the Fresnel reflectivity (used to calculate the reflectivity, electric field reflection and transmission coefficients, from the medium)

$k$ is the wave number

$s$ is the standard deviation of surface height

$m v$ is the volumetric soil moisture $(0 \ldots .1)$

$k s$ is the normalised surface standard deviation

The dependency of rough bare soil reflectivity on incidence angle, frequency and soil moisture content are shown in Figures 1, 2 , and 3 respectively. Figure 1 shows that the reflectivity of bare soil increases with incident angle. Figure 2 indicates that reflectivity of bare soil decreases with an increase in frequency. Figure 3 highlights that reflectivity of bare soil increases with an increase in soil moisture content however, the degree of increase further depends upon frequency of incident radiation. Similarly, comparison of frequency and polarisation dependence model based reflectivity values with measured reflectivity values for two specific rough bare soils are shown in Figure 4 (Hiltbrunner and Matzler 1997; Wegmuller and Matzler 1999). Both the soils have different characteristics values. For example, for soil 1, the soil temperature was $7.5^{\circ} \mathrm{C}$, incident angle was $60^{\circ}$, surface height variation was $1.3 \mathrm{~cm}$ and soil moisture content was 0.258 whilst for soil 2, the same characteristics; the soil temperature was $9.6^{\circ} \mathrm{C}$, incident angle was $60^{\circ}$, surface height variation was $1.3 \mathrm{~cm}$ and soil moisture content was 0.197. The comparison results are in good agreement. Figure 4 shows that, the reflectivity of both the soils decreases in the same pattern with an increase in frequency. A comparison result between measured and modelled reflectivity with respect to incident angle is shown in figure 5. The comparison result, as shown in figure 5 , for the incidence angle dependence model based reflectivity for bare soil with; soil temperature $5.5^{\circ} \mathrm{C}$, soil moisture content 0.38 , frequency $11 \mathrm{GHz}$ and two surface heights of 1.7 and $0.4 \mathrm{~cm}$ is well represented by the model.

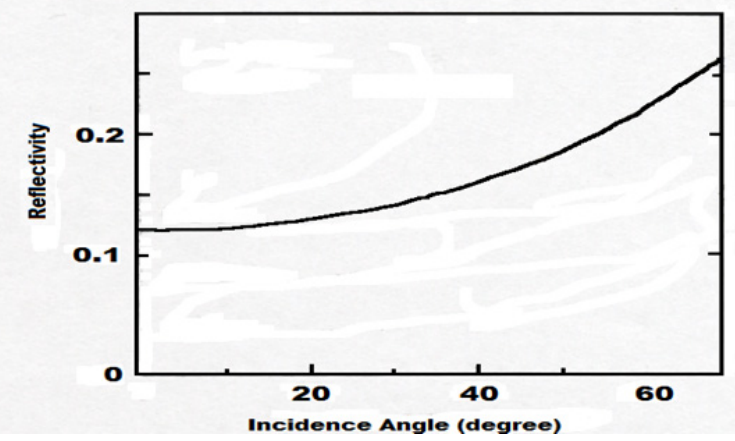

Fig. 1. The dependence of rough bare soil reflectivity on incidence angle at horizontal and vertical polarisation (Wegmuller and Matzler 1999). 


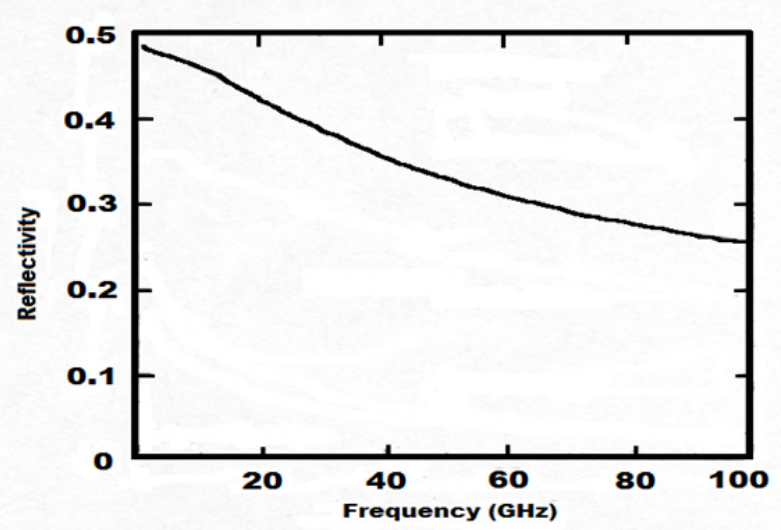

Fig. 2. The dependence of rough bare soil reflectivity on frequency at horizontal and vertical polarisation (Wegmuller and Matzler 1999).

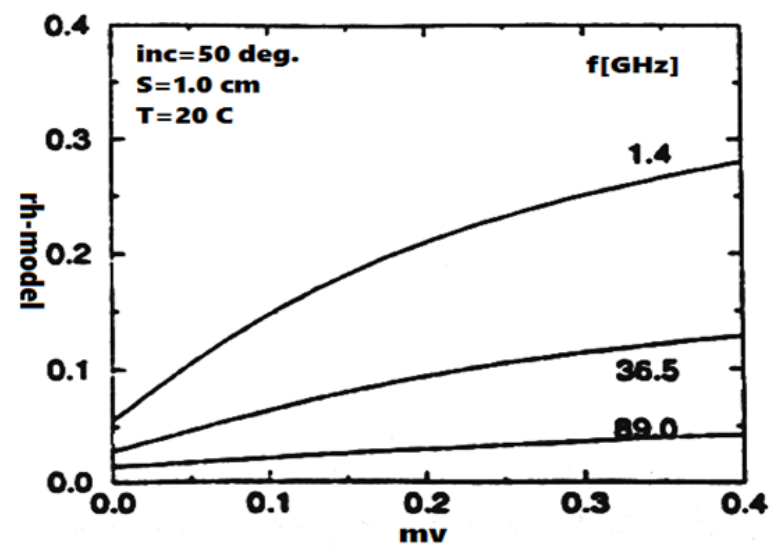

Fig. 3. The dependence of rough bare soil reflectivity on soil moisture at horizontal polarisation (Wegmuller and Matzler 1999).

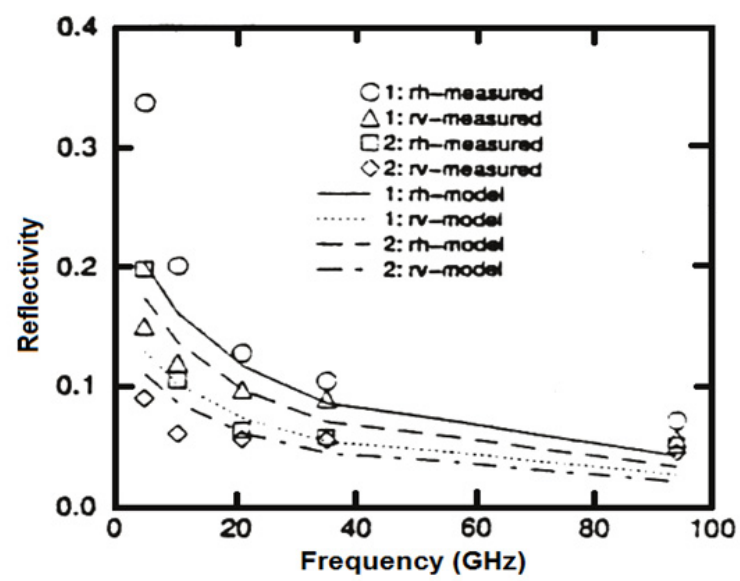

Fig. 4. Modelled and measured frequency and polarisation dependence reflectivity (Wegmuller and Matzler 1999).

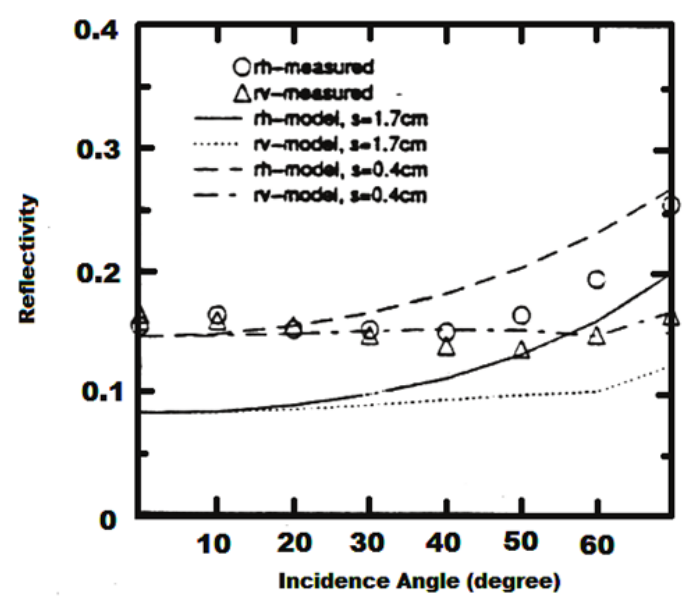

Fig. 5. Modelled and measured incidence angle and polarisation dependence of bare soil reflectivity (Wegmuller and Matzler 1999).

From equations (12), (13) and (14) we can calculate soil reflectivity at horizontal and vertical polarisation. The emissivity term can be calculated by subtracting the reflectivity from 1 (R-1) while by multiplying the emissivity values with physical temperature we can obtain the brightness temperature values. The surface under consideration may also contain forested land. The contribution from forest surface are modelled using equation (15).

$$
B_{\text {for }}=\left[1-\frac{1}{L_{\text {can }}^{2}}(1-E)\right] T_{p h y s}
$$

where

$T_{\text {phys }}=T_{s}$ is the physical temperature

$E$ is the emissivity

$L_{c a n}$ is the forest canopy loss factor

The forest canopy loss factor given by Pulliainen, et al. (1999) and Kurvonen and Hallikainen (1997) is calculated using equation (16).

$t_{\text {can }}=\frac{1}{L_{c a n}}=t(f, \infty)+[1-t(f, \infty)] e^{-0.0035 \times V o l}$

where

$f$ is the frequency

$\mathrm{Vol}$ is the forest stem volume

$t(f, \infty)=t(\infty, \infty)+[1-t(\infty, \infty)] e^{-0.028 \times f}$ 
$t(\infty, \infty)=0.42$

Similarly, the emissivity of the ground scene is calculated from equation (17).

$E_{\text {gnd }}=\left[1-\frac{1}{L_{c a n}^{2}}(1-E)\right] F_{\text {for }}+E\left(1-F_{\text {for }}\right)$

where

$F_{f o r}$ is the percentage of land surface cover by forest

$E$ is the emissivity

$L_{c a n}$ is the forest canopy loss factor

Atmospheric contribution can be divided into two parts (equation, 18 and 19); atmospheric transmissivity and atmospheric brightness temperature respectively (Louis, 1979; Anderson 1984; Schult, 1991). The atmospheric transmissivity is presented by Pulliainen, et al., (1993) as a statistical principal component model in the following equation:

$T_{k}(\gamma)=\left(T_{p}^{0}\right)_{k}+\gamma\left(T_{p}^{1}\right)^{1.0681}{ }_{k}$

where

$k$ is the frequency channel

$\gamma$ is the scalar variables that defines the constant mean atmospheric transmissivity

$T_{p}^{0}$ is the zero order principal component of atmospheric transmissivity

$T_{p}^{1}$ is the first order principal component of atmospheric transmissivity

The zero-order and first-order principal components of the atmospheric transmissivity of equation (18) are given in Table 1.

Table 1. Values of principle component of atmospheric transmissivity for different frequencies both at vertical and horizontal polarizations (from Pulliainen, et al. 1997).

\begin{tabular}{|l|l|l|l|l|l|l|l|}
\hline $\begin{array}{l}\text { Frequency } \\
\text { (GHz) }\end{array}$ & $19-\mathbf{V}$ & $\mathbf{1 9 - H}$ & $\mathbf{2 2 - V}$ & $\mathbf{3 7 - V}$ & $\mathbf{3 7 - H}$ & $\mathbf{8 5 - V}$ & $\mathbf{8 5 - H}$ \\
\hline$T_{p}^{0}$ & 0.9211 & 0.9211 & 0.8326 & 0.8624 & 0.8624 & 0.6656 & 0.6656 \\
\hline$T_{p}^{1}$ & 0.2069 & 0.2069 & 0.4642 & 0.2746 & 0.2746 & 0.8163 & 0.8163 \\
\hline
\end{tabular}

Pulliainen, et al. (1993) presented a relationship to model the up-welling and down-welling apparent temperature using statistical transmissivity values given as:

$T_{a, \text { atmos } \uparrow(\downarrow)}=\alpha \uparrow(\downarrow) T_{s}(1-T)$

where

$T_{s}$ is the surface physical temperature

$T$ is the atmospheric transmissivity

$\alpha \uparrow(\downarrow)$ are the up-welling and down-welling approximate atmospheric profile factor and is given in equation (20) and (21) (Aschbacher 1989):

$$
\begin{aligned}
& \alpha \uparrow=-0.073 T^{2}+0.101 T+0.918 \\
& \alpha \downarrow=-0.035 T^{2}+0.014 T+0.967
\end{aligned}
$$

\section{Results and Discussion}

In the process of radiative transfer theory base model, simulation the predicted brightness temperature values depends upon accuracy of the parametric values assigned during calibration. In current study, a sensitivity test therefore is essential in order to determine the impact of parameters on the estimated brightness temperatures from the model. It is understood that in a single footprint of microwave image the presence of various features may contribute in the observed brightness temperature values by the satellite. In addition, various atmospheric effects should be considered in the process of simulation. Generally, considering the coarse resolution of microwave data, four major features may be considered to contribute in a single pixel of microwave data, that is, soil, forest, water and atmosphere. However, before the results are discussed it must be noted that there are two types of parameters that is, physical parameters that provide information on the physical structure of the system, and process parameters that determine the order of magnitude of processes, which affect the movement and distribution of the input. In 
radiative transfer theory based model the process parameters must be quantified and evaluated from calibration method. The process parameters can either be established from field measurements if they bear a physical resemblance to the actual attributes of the real system or evaluated by a procedure known as optimisation. Equation (22) is used to determine the parametric effects in radiative transfer theory based microwave model. It is evident that the maximum error is produced by water followed by forest, atmosphere and soil.

$$
P_{\text {Combined }}=\sqrt{P_{\text {Soil }}^{2}+P_{\text {Forest }}^{2}+P_{\text {Water }}^{2}+P_{\text {Atmosphere }}^{2}}
$$

Our analysis show that the contributing values of these parameters is as follows;

$P_{\text {Soil }}=1.38 \mathrm{~K}$

$P_{\text {Forest }}=2.97 \mathrm{~K}$

$P_{\text {Water }}=10.33 \mathrm{~K}$

$P_{\text {Atmosphere }}=1.64 \mathrm{~K}$

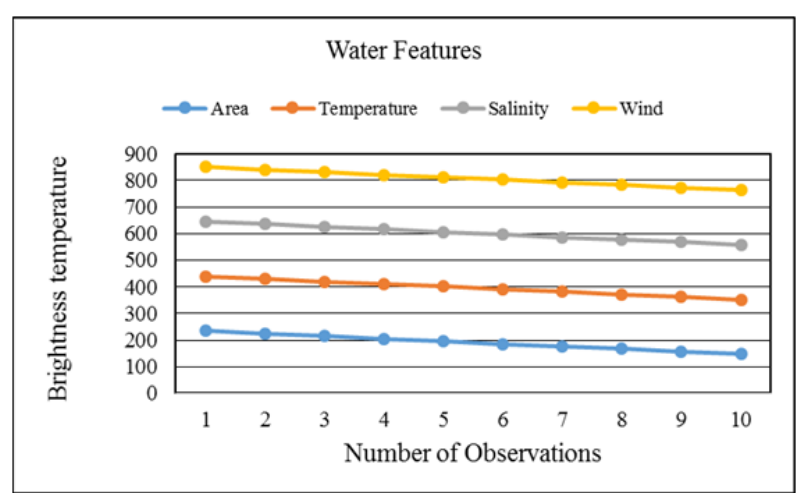

Fig. 6. Effect of water bodies on brightness temperature.

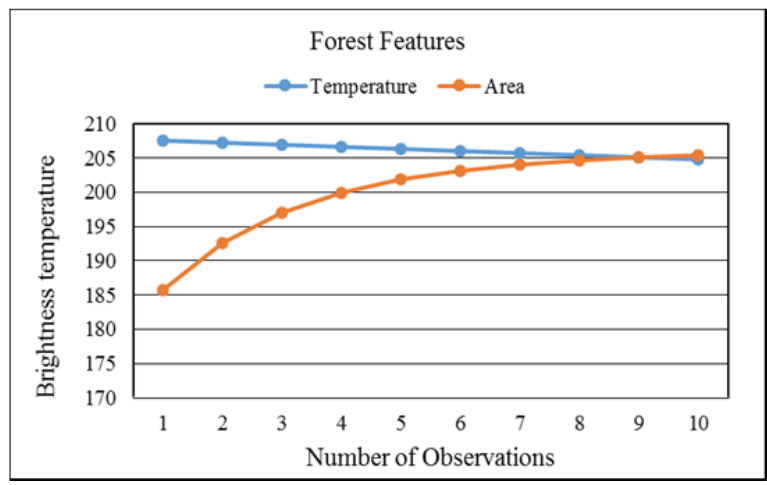

Fig. 7. Effect of forest surface on brightness temperature.
The effect of water bodies on radiative transfer theory based microwave emission model is shown in figure 6 . For a water surface the water temperature, water salinity, wind speed and area fraction covered by water body are important factors. It is evident form figure 6 that the brightness temperature decreases with an increase in water temperature, water salinity, wind speed and area fraction covered by water body. Since water is a poor emitter, the area fraction covered by water body has an immense impact on the brightness temperature measured by satellites. Typical brightness temperature are on the order of half the physical temperature of the water body. Thus, an increase in water fraction area has reverse effect on the at satellite measured brightness temperature.

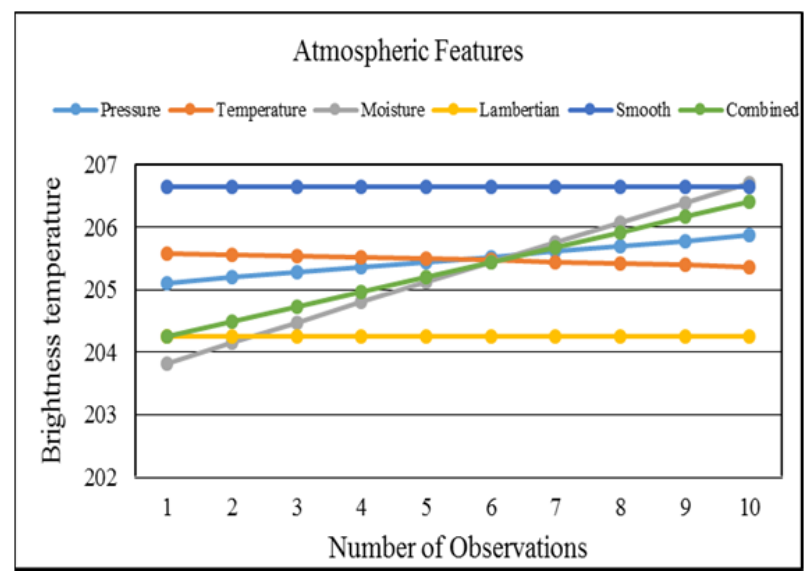

Fig. 8. Effect of atmosphere on brightness temperature.

Similarly, the effect of forest area on radiative transfer theory based microwave emission model is shown in figure 7. For a forest area the physical temperature and forest density are the important factors. It is clear from figure 7 that the brightness temperature decreases with an increase in forest temperature while it increases with an increase in the forest density (area fraction covered by forest). Since, in areas where forests are dense the scattering from the various surface features is masked by the trees which consequently has 
great impact on the at satellite measured brightness temperature.

The effect of atmosphere on radiative transfer theory based microwave emission model is shown in figure 8 . The contribution of atmosphere is a combination of various features that includes; atmospheric temperature, atmospheric pressure, atmospheric moisture, and sky type (Smooth, Lambertian, and Combined). Since, the atmosphere contributes in the upwelling brightness temperature, therefore at satellite total measured brightness temperature is increased marginally due to atmospheric effects.

Finally, the effect of soil surface on radiative transfer theory based microwave emission model is shown in figure 9. Soil effect is a combination of various features that includes; soil physical temperature, soil volumetric moisture content, and soil surface roughness. It is evident form figure 9 that the brightness temperature is decreases with an increase in soil physical temperature, soil volumetric moisture content and soil surface roughness. However, their combined effect on total brightness temperature measure at on satellite is not significant. Nevertheless, since soil is one of the major feature available in a single footprint of microwave image, its impact on brightness temperature measurements cannot be ignored.

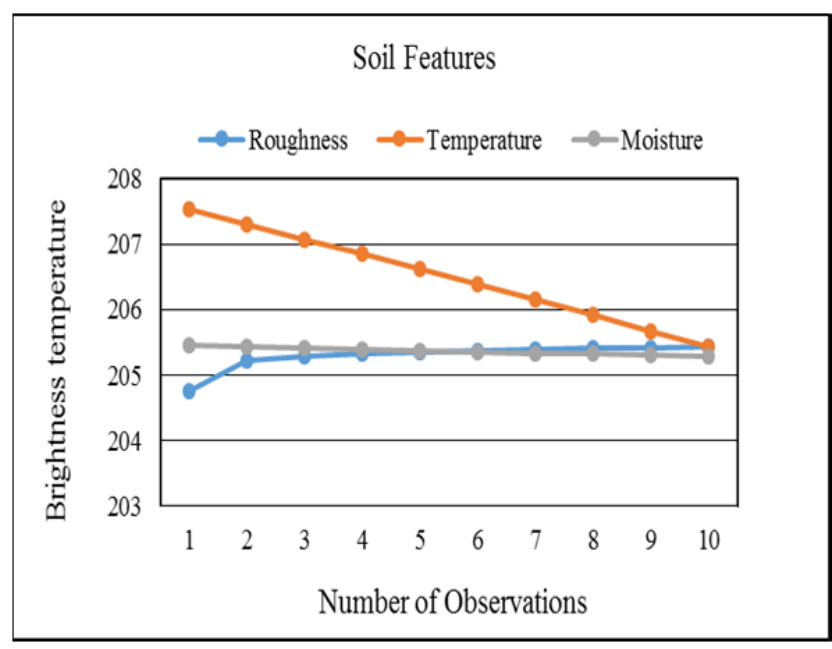

Fig. 9. Effect of soil surface on brightness temperature.
These results indicate that water area, forest cover, atmosphere and soil surface should be considered in radiative transfer theory based microwave emission model in order to simulate on satellite brightness temperature values.

\section{Conclusion}

Since the launch of the first microwave radiometer in 1972, more advanced radiometers containing additional channels and higher spatial resolution that can measure unique signatures, which provide information for the identification of surface features have been developed. The important physical principles of interaction of microwave radiation with atmosphere and surface features are addressed in current research. The volumetric and surface properties of the medium (the radiation is absorbed and scattered and then at the air-surface interface the radiation is refracted) effect the upwelling microwave radiation. The spatial resolution of the microwave radiometers is coarse, the combinations of forest, soil, water within a pixel greatly complicate the retrieval algorithm development. However, the local variations for the low spatial resolution of microwave radiometers are often of sub-pixel size and therefore the effects of urban areas, roads and wasteland can be neglected.

This research has highlighted the approach taken when using radiative transfer theory based microwave emission models to retrieve on satellite brightness temperature. Although, some weaknesses in the mentioned methodology exists, it has been used widely in research due to its simplicity and acceptable results (for example, Chang, et al., 1980; Chang, 1997, Zwally, 1977, Tiuri 1982 and Armstrong, et al. 1993). The shortcomings of microwave emission model are effects of regional conditions and poor spatial resolution. However, many researchers have used radiative transfer theory based microwave 
emission model to retrieve brightness temperature (for example, Kunzi, et al. 1982, Hallikainen, et al., 1985, Chang, 1997, Aschbacher, 1989, Goodison, 1989, Rott, et al. 1991, Pulliainen et al. 1999). The main contributing features in the model are:

1. Contribution from water surface

2. Contribution from forest area

3. Soil surface contribution

4. Atmospheric contribution

Atmospheric and forest area contributions enables the use of the radiative transfer theory base microwave model to interpret the spaceborne radiometer observations. Many researchers have found good agreement when model predictions are compared with independent experimental emission data and space-borne observations (Liebe, 1988; 1989). The model developed by Wegmuller and Matzler (1999) was used to incorporate the soil reflectivity between the frequency range of 1-100 GHz at horizontal and vertical polarisation. Although, the model has certain limitations as it fails to predict the high reflectivity values observed for soils that are smoothed by repeated precipitation on bare fields during winter season. On the other hand, forest effect was incorporated using the method given by Kurvonen and Hallikainen, (1997) after making angular correction. Atmospheric factors have been addressed by using methods given in Pulliainen, et al. (1997) and Aschbacher (1989) of statistical inversion that can be used for any application area and with any set of channels. Since the model includes contribution from water, soil, forest and atmosphere, it is expected that this model has potential to be applied for the retrieval of at satellite brightness temperature information as reported by other researchers for example, Jiang, et al., 2007; Proksch, et al., 2015; Morgachev, et al., 2015.

\section{References}

Anderson, D. M. and Tice, J. A. (1971) Low Temperature Phases Of Interfacial Water In Clay-Water System, Soil Science Society of American Proceeding, 35, 47.

Anderson, T. (1984) An Introduction to multivariate statistical analysis, 2nd edition. New York: John Wiley \& Sons.

Armstrong, R. L., Chang, A. T. C., Rango, A. and Josberger, E. (1993) Snow depth and grain size relationships with relevance for passive microwave studies, Analysis of Glaciology, 17: 171-176.

Aschbacher, J. (1989) Land Surface Studies and Atmospheric Effects by Satellite Microwave Radiometry, PhD Dissertation, University of Innsbruck, Austria.

Barnes, J. C., Bowley, C. J., Smallwood, M. D. and Willand, J. H. (1981) Snow hydrology studies using data from the heat capacity mapping mission, Proceedings of IEEE'81, PP: 1211-1217.

Butt, M. J. (2002a) Investigation of the Effects of Rough Bare Soil Reflectivity Model, Journal of Pure and Applied Sciences, 21 (2): 13-25.

Butt, M. J. (2002b) Sensitivity Analysis of Brightness Temperature Retrieval Algorithm, Journal of Science International-Lahore, 14 (4): 279-282.

Butt, M. J. (2002c) The Role of Atmosphere on Upwelling Microwave Radiations, Journal of Pure and Applied Sciences, 21 (2): 13-23.

Chang, A. T. C. (1997) Snow parameters derived from Microwave measurements during the Boreas winter field campaign, Journal of Geophysical Research, 102 (D24):29663-29671.

Chang, A. T. C., Choudhury, B. J. and Gloersen, P. (1980) Microwave brightness of polar firn as measured by Nimbus-5 and -6 ESMR, Journal of Glaciology, 25 (91): $85-91$

Colton, M. C. and Poe, G. A. (1999), Intersensor calibration of DMSP SSM/I's: F-8 to F14, 1987-1997, IEEE Transactions on Geoscience and Remote Sensing, 37 (1): 418-439.

Davis, J. L., Topp, G. C. and Annan, A. D. (1976) Electromagnetic Detection Of Soil Water Content Progress Report Ii, Workshop Proceeding of Remote Sensing of Soil Moisture And Groundwater, Toronto, Canada.

Ding, K. H., Xu, X. and Tsang, L. (2010) Electromagnetic scattering by bicontinuous random microstructures with discrete permittivities, IEEE T. Geosci. Remote, 48: 3139 3151 .

Fung, A. K. and Chen, M. F. (1981) Emission from an inhomogeneous layer with irregular interfaces, Radio Science, 16: 289-298. 
Goodison, B. E. (1989) Determination of areal snow water equivalent on the Canadian Prairies using passive Microwave satellite data, IEEE IGARSS'89 Digest, 12431246.

Hallikainen, M. T. (1989) Microwave radiometry of snow, Advances in space Research, 9 (1): 267-275.

Hallikainen, M. T., Ulaby, F. T., Dobson, M. C., El-Rayes, M. A. and Wu, L. K. (1985) Microwave dielectric behaviour of wet soil Part-I Empirical models and experimental observations, IEEE Transactions on Geoscience and Remote Sensing, 23 (1): 25-34.

Hiltbrunner, D. and Matzler, C. (1997) Land surface temperature retrieval and snow discrimination using SSM/I data, Proceeding of the EARSeL Workshop Remote Sensing of Land Ice and Snow, University of Freiburg Germany, PP: 87-94.

Hoekstra, P. and Delaney, A. (1974) Dielectric properties of soils at UHF and microwave frequencies, Journal of Geophysical Research, 79: 1699-1708.

Hollinger, J. P., Peirce, J. L. and Poe, G.A. (1990) SSM/I Instrument Evaluation, IEEE Transactions on Geoscience and Remote Sensing, 28 (5): 781-790.

Jiang, L., Shic, J., Tjuatjad, S., Doziere, J., Chenf, K. and Zhang, L. (2007) A parameterized multiple-scattering model for microwave emission from dry snow, Journal of Remote Sensing of Environment, 111: 357-366.

Jin, Y. Q. and Zhang, N. (1999) Correlation of the ERS and SSM/I Observations over Snow Pack and Numerical Simulation, International Journal of Remote Sensing, 20 (15/16): 3009-3018.

Kokhanovsky, A. (2001) Optics of Light Scattering Media: Problems and Solutions, 2nd edition. Springer-Praxis, Chichester, UK.

Kumar, S., Sahoo, P. K. and Singh, R. P. (1999) Monitoring of Brightness temperature Over Indian and Adjoining Regions Using SSM/I Data, International Journal of Remote Sensing, 20 (12): 2305-2307.

Kunzi, K. F., Patil, S. and Rott, H. (1982) Snow cover parameters retrieved from Nimbus-7 Scanning Multichannel Microwave Radiometer (SMMR) data, IEEE Transactions on Geoscience and Remote Sensing, 20 (4): 452-467.

Kurvonen, L. and Hallikainen, M. (1997) Influence of land cover category on brightness temperature of snow, IEEE Transactions on Geoscience and Remote Sensing, 35 (2): 367-377.

Lakshmi, V., Wood, E. F. and Choudhury, B. J. (1997) Investigation of Effect of Hetrogeneities in Vegetation and Rainfall on Simulated SSM/I Brightness Temperatures, International Journal of Remote Sensing, 18 (13): 27632784.
Lemmetyinen, J., Kontu, A., Leppänen, L., Pulliainen, J., Wiesmann, A., Werner, C., Proksch, M. and Schneebeli, M. (2013) Technical assistance for the development of an $X$ - to Ku-Band Scatterometer during the NoSREx III experiment, ESA ESTEC: Noordwijk, Netherlands.

Leschanskiy, Y. I., Lebedeva, G. N. and Schumilin, V. D. (197) Electrical parameters of sandy and loamy soils in the range of centimetre, decimetre and meter wavelength, $I z v$. Vyss. Ucheb. Zaved. Radiofiz, 14 (4): 562-569.

Liebe, H. J. (1988) Atmospheric Attenuation and Delay Rates Between $1 \mathrm{GHz}$ and $1 \mathrm{THz}$. Conference proceeding on Microwave Propagation in the Marine Boundary Layer, Monterey, CA, USA.

Liebe, H. J. (1989) MPM-An Atmospheric Millimeter-Wave Propagation Model, International Journal of Infrared and Millimeter Waves, 10: 631-650.

Loth, B. and Graf, H. F. (1998) Modeling the snow cover in climate studies 1 . Long-term integration under different climate conditions using a multilayered snow cover model, Journal of Geophysical Research, 103 (D10): 1131311327.

Louis, J. F. (1979) A Parametric Model of Vertical eddy Fluxes in the Atmosphere Boundary Layer, Boundary Layer Meteorology, 17: 187-202.

Lundien, J. R. (1971) Terrain Analysis by Electromagnetic Means, U.S. Army Engineer Waterways Experiment Station, Vicksburg, MS, PP: 3-727.

Matzler, C. (1990) Study of microwave interaction with Earth's surface: Algorithms for retrieving snowpack properties from a Multichannel Imaging Microwave Radiometer (MIMR), ESA, Study Contract No. 8447/89/NL/PB/(SC).

Matzler, C. (1992) Passive Microwave Signature Retrieval Catalog 1989-1992, Institute of Applied Physics: Univ. of Bern. Switzerland.

Mätzler, C. (2005) On the determination of surface emissivity from Satellite observations, IEEE Geosci. Remote Sensing, 2:160-163, doi:10.1109/LGRS.2004.842448.

Mätzler, C. and Melsheimer, C. (2006) Radiative transfer and microwave radiometry, In: Thermal Microwave Radiation Applications for Remote Sensing, ET Electromagnetic Waves Series, Institution of Engineering and Technology (IET), London, UK, pp. 52:1-23.

Mätzler, C. and Rosenkranz, P. (2007) Dependence of microwave brightness temperature on bistatic surface scattering: model functions and application to AMSU-A, IEEE T. Geosci. Remote, 45: 2130-2138.

Mironov, V., DeRoo, R. and Savin, I. (2010) Temperaturedependable microwave dielectric model for an Arctic soil, IEEE T. Geosci. Remote, 48: 2544-2556. 
Morgachev, A. S., Kuznetsov, S. A., Melnikov, V. F. and Simões, J. A. (2015) Modeling the distribution of circular polarization degree of microwave emission along the flare loops in event July 19, 2012, Geomagnetism and Aeronomy, 55 (8): 1118-1123.

Newton, R. W. (1977) Microwave Remote Sensing and its Application to Soil Moisture Detection, Texas A \& M University, RSC-81.

Picard, G., Brucker, L., Roy, A., Dupont, F., Fily, M., Royer, A. and Harlow, C. (2013) Simulation of the microwave emission of multi-layered snowpacks using the Dense Media Radiative transfer theory: the DMRT-ML model, Geosci. Model Dev., 6: 1061-1078.

Proksch, M., Mätzler, C. Wiesmann, A., Lemmetyinen, J., Schwank, M., Löwe, H. and Schneebeli, M. (2015) MEMLS3\&a: Microwave Emission Model of Layered Snowpacks adapted to include backscattering, Geosci. Model Dev., 8: 2611-2626.

Pulliainen, J. T., Grandell, J. and Hallikainen, M. T. (1999) HUT Snow Emission Model and its Applicability to Snow Water Equivalent Retrieval, IEEE Transactions on Geoscience and Remote Sensing, 37 (3): 1378-1390.

Pulliainen, J. T., Grandell, J. and Hallikainen, M. T. (1997) Retrieval of surface temperature in boreal forest zone from $\mathrm{SSM} / \mathrm{I}$ data, IEEE Transactions on Geoscience and Remote Sensing, 35 (5): 1188-1200.

Pulliainen, J., Karna, J. P. and Hallikainen, M. T. (1993) Development of Geophysical retrieval algorithm for the MIMR. IEEE Transactions on Geoscience and Remote Sensing, 31 (1): 268-277.

Rees, W. G. (1993) Physical Principles of Remote Sensing. Cambridge University Press, Cambridge.

Rott, H., Nagler, T. and Aschbacher, J. (1991) Algorithm development for monitoring global snow cover by spaceborne microwave radiometry, Proceeding of the 11th EARSeL Symposium. Graz, Austria.

Schiavon, G., Ferrazzoli, P., Solimini, D., de Maagt, P. and Baptista, J. P. V. P. (1998) A Global High-Resolution Microwave Emission Model for the Earth, Radio Science, 33 (3): 753-766.

Schult, I. (1991) Formation and Transport of Aerosol Particles in the Stratosphere and their Influence on the Radiation Budget Examamination Arb II, Max-PlanckInstitute for Meteorology, Hamburg, Germany, 142.

Standley, A. P. and Barrett, E. C. (1999) The use of coincident DMSP SSM/I and OLS satellites data to improve snow cover detection and discrimination, International Journal of Remote Sensing, 20 (2): 285-305.

Stotzer, E., Wegmuller, U., Huppi, R. and Matzler, C. (1986) Dielectric and surface parameters related to microwave scatter and emission properties, proceeding of IGARSS ESA SP-254, Zurich, Switzerland, PP: 599-603.

Tiuri, M. E. (1982) Theoretical and experimental studies of microwave emission signatures of snow, IEEE Transactions on Geoscience and Remote Sensing, 20 (1): 51-57.

Ulaby, F. T., Moore, R. K. and Fung, A. K. (1986a) Microwave remote sensing: active and passive. Massachusettes: Artech House Inc., 3, 1097.

Ulaby, F. T., Moore, R. K. and Fung, A. K. (1986b) Microwave remote sensing: fundamentals and radiometry. Massachusettes: Artech House Inc. 1.

Ulaby, F.T., Moore, R.K. and Fung, A. K. (1981) Microwave Remote Sensing, Vol. 1.

Wegmuller, U. (1986) Signaturen zur MikrowellenFernerkundung: Boden-rauhigkeit und Permittivitat von Eis. Diploma Thesis, Institute of Applied Physics, University of Bern, Bern, Switzerland.

Wegmuller, U. and Matzler, C. (1993) Active and passive microwave signature catalog 2-12 $\mathrm{GHz}$, University of Bern: Bern, Switzerland.

Wegmuller, U. and Matzler, C. (1999) Rough bare soil reflectivity model, IEEE Transactions on Geoscience and Remote Sensing, 37 (3): 1391-1395.

Wiesmann, A. and Mätzler, C. (1999) Microwave Emission Model of Layered Snowpacks, Remote Sens. Environ., 70: 307-316.

Yang, Z. L., Dickinson, R. E., Robock, A. and Vinnikov, K. Y. (1997) On Validation of the Snow Sub Model of the Biosphere-Atmosphere Transfer Scheme with Russian Snow Cover and Meteorological Observations Data, American Meteorological Society, 10: 353-373.

Zwally, H. (1977) Microwave emissivity and accumulation rate of polar firn, Journal of Glacialogy, 18: 195-215.

Rautiainen, K., Lemmetyinen, J., Pulliainen, J., Vehviläinen, Drusch, M., Kontu, A., Kainulainen, J. and Seppänen, J. (2012) L-band radiometer observations of soil processes in boreal and subarctic environments, IEEE T. Geosci. Remote, 50:1483-1497, doi:10.1109/TGRS.2011.2167755. 


\title{
تأثثر العوامل الطبيعية المختلفة على نظرية انتقال الأشعة المبنية على نموذج إثعاع موجات الميكروويف
}

مازن إبراهيم عسيري

\author{
قسم الأرصاد، كلية الأرصاد والبيئة وزراعة المناطق الجافة، جامعة الملك عبدالعزيز، \\ جلة، المملكة العربية السعودية
}

Massiri1@kau.edu.sa

الستخلص. في هذه الورقة تم البحث في نمذجة التبادل الإثعاعي الكهرومغناطيسي بين الأرض وغلافها الجوي. فمن بين أنواع الموجات المختلفة نجد أن صور موجات الميكرويف السلبية مصدر معلوماتي مفيد لرسم خرائط طبيعة الأرض وسماتها المميزة بشكل دقيق. وبما أن الإثارات المستقبلة بواسطة مجس النسات الموجات الطويلة تنكون من إنتارات صادرة من سطح الأرض والغلاف الجوي فإن التفسير الصحيح لهذه

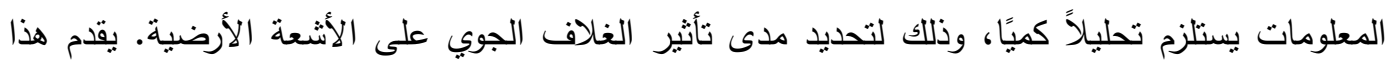

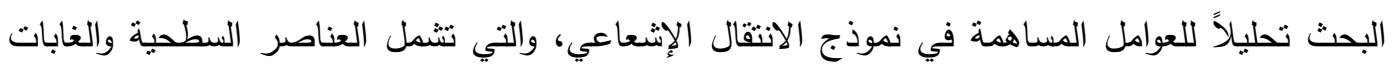
والمسطحات المائية بالإضافة إلى عناصر الغلاف الجوي. ويتمنل الهدف الرئيس من هذه الدراسة قياس

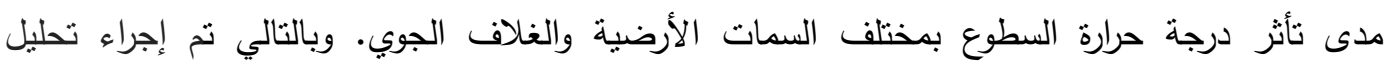

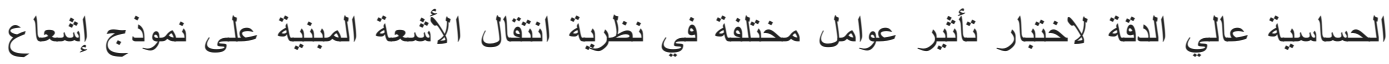

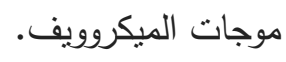

أظهرت نتائج الدراسة أن درجة حرارة التربة والغطاء النباتي هي المعايير الرئيسة المؤثرة في تقدير درجة

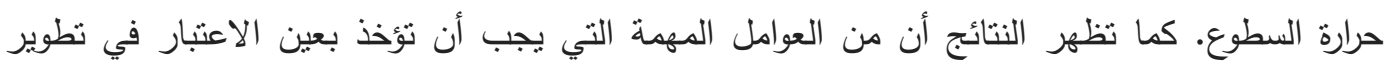
وتطبيق نماذج انتقال الإثعاع هي الخصائص والصفات الأرضية وعناصر الغلاف الجوي. كلمات إرشادية: موجات ميكروويف، كهرومغناطيسي، غلاف جوي، انتقال الأثشعة، حرارة السطوع، حرارة التزبة، غطاء نباني. 